\title{
Het Gereflecteerde Lichaam
}

Citation for published version (APA):

Zwijnenberg, R. (2000). Het Gereflecteerde Lichaam. Universiteit Maastricht. https://doi.org/10.26481/spe.20000317rz

Document status and date:

Published: 17/03/2000

DOI:

10.26481/spe.20000317rz

Document Version:

Publisher's PDF, also known as Version of record

\section{Please check the document version of this publication:}

- A submitted manuscript is the version of the article upon submission and before peer-review. There can be important differences between the submitted version and the official published version of record.

People interested in the research are advised to contact the author for the final version of the publication, or visit the DOI to the publisher's website.

- The final author version and the galley proof are versions of the publication after peer review.

- The final published version features the final layout of the paper including the volume, issue and page numbers.

Link to publication

\footnotetext{
General rights rights.

- You may freely distribute the URL identifying the publication in the public portal. please follow below link for the End User Agreement:

www.umlib.nl/taverne-license

Take down policy

If you believe that this document breaches copyright please contact us at:

repository@maastrichtuniversity.nl

providing details and we will investigate your claim.
}

Copyright and moral rights for the publications made accessible in the public portal are retained by the authors and/or other copyright owners and it is a condition of accessing publications that users recognise and abide by the legal requirements associated with these

- Users may download and print one copy of any publication from the public portal for the purpose of private study or research.

- You may not further distribute the material or use it for any profit-making activity or commercial gain

If the publication is distributed under the terms of Article $25 \mathrm{fa}$ of the Dutch Copyright Act, indicated by the "Taverne" license above, 


\section{HET GEREFLECTEERDE LICHAAM}


(c) 2000, R. Zwijnenberg

ISBN 9090135537

Alle reehten voorbehouden. Niets uit deze uitgäve mag worden verveelvoudigd, opgeslagen in een geautomatiseerd gegevensbestand, of openbaar gemaakt in enige vorm of op enige wijze, hetzij elektronisch, mechanisch, door fotokopieën, opnamen, of enig andere manier, zonder voorafgaande toestemming van de auteur. 


\section{HET GEREFLECTEERDE LICHAAM}

\section{REDE}

uitgesproken bij de aanvaarding van het ambt van bijzonder hoogleraar kunstgeschiedenis in relatie tot de ontwikkeling van natuurwetenschap en techniek aan de Faculteit der Cultuurwetenschappen van de Universiteit Maastricht op vrijdag 17 maart 2000

door

Dr. Robert Zwijnenberg 

Mijnheer de Rector Magnificus,

Zeer gewaardeerde toehoorders,

Vandaag zal ik met het uitspreken van deze rede het ambt aanvaarden van bijzonder hoogleraar kunstgeschiedenis in relatie tot de ontwikkeling van natuurwetenschap en techniek.

$U$ heeft de weidse omschrijving van het ambt dat ik vanniddag blijmoedig ga aanvaarden reeds kunnen lezen in de uitnodiging voor deze voor mij bijzondere bijeenkomst. $U$ heeft zich misschien afgevraagd wat dit ambt moet inhouden, gezien deze omschrijving. Vanmiddag wil ik, als u mij toestaat, een aantal van mijn gedachten over deze leeropdracht aan $u$ voorleggen.

De relatie tussen kunst en wetenschap staat op dit moment bijzonder in de belangstelling. Dat blijkt bijvoorbeeld uit het feit dat er in de afgelopen tijd ook in Nederland een aantal tentoonstellingen is geweest dat deze relatie tot thema had, bijwoorbeeld 'Sporen van wetenschap in kunst', georganiseerd door de KNAW in haar gebouw in Amsterdam (juni-augustus 1998), en 'Neuro-Artonomy', een tentoonstelling van kunstenaars en hersenwetenschappers in de Erasmus Universiteit te Rotterdam (augustus-september 1998) "Wat echter opvalt bij deze exposities is dat het vooral gaat om de plaats van de wetenschap in de kunst. Ze laten zien op welke wijze wetenschappelijke theorieën en resultaten daarvan, in verschillende vormen van kunst terug zijn te vinden.

Op deze tentoonstellingen zijn daarentegen 'sporen van kunst in wetenschap' veel minder uitgesproken aanwezig. Dat is ook niet zo vreemd: het is eenvoudiger om een technische installatie of een wetenschappelijk experiment te transformeren tot kunstwerk, dan andersom. Het kunstwerk als kunstwerk (en niet als materieel object) laat zich niet zo makkelijk omvormen tot een apparaat dat wetenschappers daadwerkelijk kunnen gebruiken.

In de literatuur is de laatste jaren eveneens veel aandacht besteed aan 'wetenschap in kunst', maar ook, anders dan bij bovengenoemde 
exposities het geval was, aan 'kunst in wetenschap' ' $Z$ Zo zijn de verschillen en de overeenkomsten tussen wetenschappelijke afbeeldingen en artistieke voorstellingen en hun cognitieve betekenissen, het gebruik van artistieke conventies in wetenschap en van wetenschappelijke theorieën in kunst en de invloed van kunst en wetenschap op elkaars ontwikkeling uitgebreid onderzocht.

In de recente literatuur valt verder op dat het two-cultures-debat niet langer wordt gevoerd. Dat is het debat, in 1959 geopend door C.P. Snow met een lezing getiteld 'The Two Cultures', waarin kunst en wetensehap als tegengesteld aan elkaar worden voorgesteld (kunst ontdekt, wetenschap vindt uit) en waarin wordt geopperd dat kunst en wetenschap hun identiteit gedeeltelijk ontlenen aan deze oppositie.

Ook ik zal de oppositie tussen kunst en wetenschap niet als uitgangspunt nemen maar me richten op de plaatsen waar kunst en wetenschap samenkomen. Een onderzoek naar de relatie en overeenkomsten tussen kunst en wetenschap moet een onderzoek zijn naar de wijze waarop wij ons verhouden tot de wereld en de manier waarop wij vervlochten zijn met de wereld, hoe wij zelf uit de wereld voortkomen en de wereld uit ons en hoe vormgevende activiteiten als kunst en wetenschap daarin een rol spelen.

Ik zou willen voorstellen om het vraagstuk van de relatie tussen kunst en wetenschap zowel vanuit systematisch als vanuit historisch oogpunt te gaan onderzoeken. Elke historische periode heeft haar eigen opvattingen over kunst en wetenschap die overigens niet zonder meer zijn terug te voeren op een gemeenschappelijke Zeitgeist of op socioeconomische krachten. Daarom moet de vraag naar hun relatie in eerste instantie vanuit een historisch perspectief worden gesteld. Door een historisch onderzoek kunnen onverwachte zaken aan het licht komen en verhelderende inzichten worden gevonden. Deze kunnen ons helpen om hedendaagse ontwikkelingen te begrijpen en vanuit nieuwe invalshoeken te benaderen. De geschiedenis is een stevige ondergrond die ons in staat stelt om al te wilde of gebrekkige ideeën, ingegeven door de waan van de dag, te relativeren en te bekritiseren. 
We kunnen ons zo beschermen tegen het vormen van essentialistische ideeën omtrent kunst en wetenschap. Aandacht voor de geschiedenis van de relatie tussen kunst en wetenschap kan ons bovendien behoeden voor het opnieuw uitvinden van het wiel: tenslotte is alles al een keer gezegd en gedaan.

Vanmiddag wil ik u de plaats tonen waar kunst en wetenschap elkaar op de meest duidelijke wijze ontmoeten, om deze plaats vervolgens als uitgangspunt te kunnen nemen voor een onderzoek naar de relatie tussen kunst en wetenschap. Om alvast een tipje van de sluier op te lichten: deze plaats is het menselijk lichaam.

Als we spreken over de relatie tussen kunst en wetenschap, de wijze waarop kunst in wetenschap en wetenschap in kunst zichtbaar wordt, dan valt al snel de naam van Leonardo da Vinci (1452-1519). Leonardo is het meest voor de hand liggende voorbeeld van een kunstenaar die ook wetenschapper en een wetenschapper die ook kunstenaar is. Hij leefde in een periode die direct vooraf ging aan het ontstaan van de klassieke wetenschap, waarmee namen als Galilei en Newton zijn verbonden. Hij leefde bovendien in een periode waarin het onderscheid tussen kunst en wetenschap nog niet was uitgekristalliseerd in de scheiding die wij nu ervaren. Zo doet Leonardo veel moeite om aan te tonen dat schilderkunst een wetenschap is, die is gebaseerd op wiskundige principes en wordt geleid door allerlei theoretische overwegingen.

In Leonardo's tijd bevond de wetenschap zich in een crisis. Aan de ene kant werd er steeds sterker getwijfeld aan de Middeleeuwse natuurfilosofie en wetenschappelijke kennis. Er ontstonden nieuwe wetenschappelijke inzichten en er werden ontdekkingen gedaan die in strijd waren met de traditionele wetenschappelijke kennis. Aan de andere kant bleef de Middeleeuwse wetenschap toch het gezaghebbende kader. Er was nog geen nieuw wetenschappelijk paradigma, om het zo eens uit te drukken, waarin de nieuwe inzichten en ontdekkingen een plaats en functie konden hebben. Deze crisis is duidelijk zichtbaar in de manuscripten van Leonardo, waarin hij onder meer 
worstelt met het feit dat zijn anatomische ontdekkingen in tegenspraak zijn met de geldende Galeense leer. Deze crisis blijkt ook uit de wijze warop hij een artistieke en wetenschappelijke benadering van de werkelijkheid in elkaar laat overgaan. Leonardo heeft geen vast omlijnde ideeën omtrent de eigen grenzen en beperkingen van wetenschap en kunst. Deze tussenpositie maakt Leonardo, in mijn ogen, geschikt om op grond van zijn werk thema's te formuleren die ons de weg kunnen wijzen in een historisch en systematisch onderzoek naar de relatie tussen kunst en wetenschap.

In één van zijn manuscripten, ms. B, folio $28 \mathrm{r}$ (circa 1487-90) staat een onooglijk schetsje (ca. $4,5 \mathrm{~cm}$ hoog) van wat zich het best laat omschrijven als een spiegelkamer (afbeelding 1). Het is weliswaar een onooglijk schetsje maar het is een uitvinding met een hallucinerend effect op de beschouwer; zowel op de beschouwer in het apparaat als op de beschouwer van het apparaat (in ieder geval op deze beschouwer). Het is een apparaat dat zowel een bijzondere visuele en kinetische ervaring van het lichaam genereert als een onverwachte intellectuele reflectie op het lichaam oproept.

Leonardo beschrijft en tekent een apparaat dat is gemaakt door acht vlakke rechthoekige spiegels ( 2 braccia breed en 3 hoog) rechtop langs de omtrek van een cirkel (omtrek 16 braccia, doorsnede 5 braccia) te plaatsen zodat een gesloten achthoek ontstaat. Iemand die in dit apparaat staat, schrijft hij (in zijn gebruikelijke spiegelschrift), 'zal elke kant van zichzelf een oneindig aantal malen kunnen zien' (quelomo che si trovera potrassi vedere perogni verso jfinjte volte). ${ }^{3}$ Wie in het apparaat staat wordt op een zeer directe wijze - door een oneindige spiegeling van alle kanten - geconfronteerd met zijn lichaam. ${ }^{4}$

De tekening van de spiegelkamer is in de eerste plaats een bijzonder autobiografisch document. Als we aannemen dat Leonardo zich voorstelde dat de figuur niet over de spiegelwanden heen kon kijken (zoals uit de tekening blijkt) en als we aannemen dat Leonardo het apparaat voor eigen gebruik heeft ontworpen (dat wil zeggen afgestemd op zijn eigen lichaam), dan kunnen we concluderen dat Leonardo niet groter 


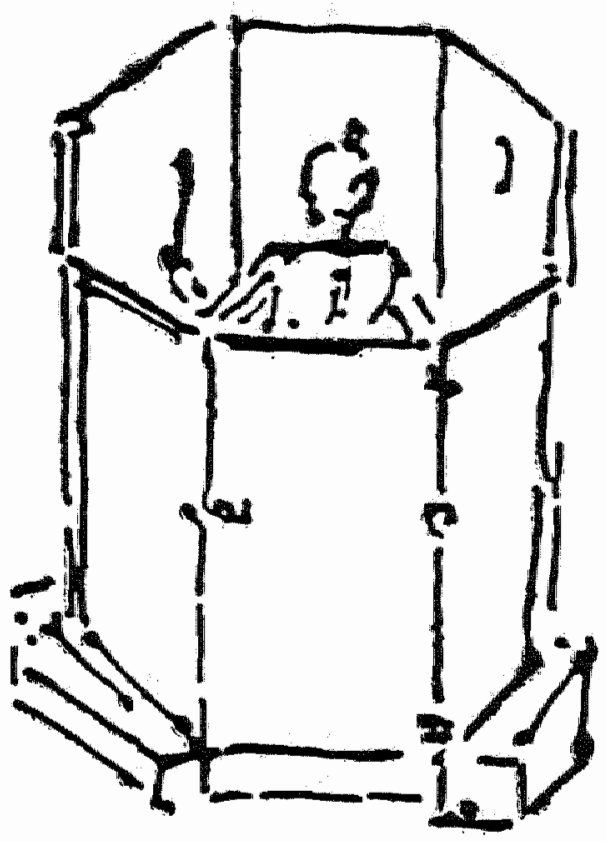

Afbeelding 1: Leonardo da Vinci, Ms B, $\mathrm{f}$. $28 \mathrm{r}$, circa $1487-90$ 
was dan 3 braccia (dat is circa $3 \times 0,58 \mathrm{~cm}=1,74 \mathrm{~m}$ ). Het apparaat vertelt ons iets over Leonardo"s lichaam, dat we langs andere weg niet weten, omdat één van de parameters wan het ontwerp van het apparaat de lengte van zijn lichaam is.

Als Leonardo in zijn spiegelkamer gaat staan, ervaart hij zijn lichaam bovendien op een heel bijzondere wijze. Hij ervaart zijn lichaam als iets dat hij heeft, waarvan de buitenkant tot in het oneindige wordt gespiegeld op een wijze die hij kan beïnvloeden maar niet totaal kan controleren; dat is het lichaam als object van de ervaring. Tegelijkertijd zal hij zichzelf ervaren als de kern van alle spiegelingen. Er is een lichaam dat hij juist niet ziet maar dat hij is en dat de oorzaak is van alle spiegelingen; dat is het lichaam als subject van de ervaring.

Het zal in het begin - staande in het midden van het apparaat - echter moeilijk zijn om de grenzen van het lichaam te bepalen: waar eindigt het eigen lichaam en waar beginnen de spiegelingen? Het lichaam vervloeit met de omgeving die slechts bestaat uit oneindige spiegelingen van dat lichaam. Je ziet jezelf alleen als spiegeling, je ervaart jezelf als spiegeling. De uitgebreidheid van je eigen lichaam vloeit samen met de uitgebreidheid van het apparaat; waardoor de innerlijke ervaring van je eigen lichaam wordt gedecentreerd. Waar ben ik, waar sta ik, welke spiegeling ben ik of bevat mijn ik?

In eerste instantie is het eigen lichaam in de spiegelkamer een oneindig uitgebreid spookachtig fenomeen waarin we volledig opgaan en waarop we geen greep meer hebben. Het vergt enige tijd, oefening en denkkracht om de verhouding tussen de spiegelingen en het eigen lichaam te ervarèn en in greep te krijgen.

Daarvoor is nodig dat we ons terugtrekken in de ervaring van onze eigen bewegingen, om zo het lichaam dat direct wordt ervaren los te koppelen van zijn spiegelingen, zodat er slechts een visuele koppeling blijft bestaan. We moeten onze eigen beperkte lichamelijke uitgebreidheid opnieuw veroveren door haar af te grenzen van haar oneindige spiegelingen. 
Als we dat hebben bereikt, merken we dat er "onmogelijke" perspectieven op het eigen lichaam mogelijk zijn. Door middel van de spiegelingen kunnen we een blik op en een ervaring van ons lichaam hebben die we normaal alleen van de dingen kunnen hebben. We kunnen onszelf van alle kanten bekijken zonder dat we ons lichaam hoeven te bewegen, of zonder dat we als het ware uit ons lichaam hoeven te treden. In de spiegelkamer hebben we alle onmogelijke gezichtspunten van ons lichaam - zoals de achterkant, ons hoofd - tegelijkertijd tot onze beschikking. Dit in tegenstelling tot wanneer we onszelf in een gewone spiegel bekijken. Dat wil zeggen dat in de spiegelkamer 'het zien" wordt geintensiveerd. We zien meer van ons lichaam dan we in de wereld buiten de spiegelkamer ooit kunnen zien zonder te bewegen, en als we al bewegen, verandert alles op oneindig veel manieren, op een wijze die ook volledig afwijkt van wat we zijn gewend. Het kijken zelf wordt als ervaring op de voorgrond geplaatst, we ervaren allereerst vooral dat we kijken en niet - zoals in de wereld buiten de spiegelkamer - wat we zien.

Door middel van de spiegelkamer kan Leonardo zodoende de twee fundamentele manieren waarop we ons lichaam kunnen ervaren (die ik eerder heb genoemd) op een heel directe wijze gewaarworden en onderzoeken: het lichaam als object en als subject van de ervaring. We hebben als mens een lichaam en we zijn als mens een lichaam. ${ }^{5}$ Het lichaam als subject van de ervaring (dat we een lichaam zijn) stelt ons instaat om de wereld en ons eigen lichaam te ervaren als object (dat we een lichaam hebben). We moeten ons terugtrekken in het lichaam als subject van de ervaring om greep te krijgen op de wervelende spiegelingen. Dit subject van de ervaring is de mogelijkheid van ons zien en zal ook in de spiegelkamer altijd onzichtbaar blijven, het is de blinde vlek wan ons alziend spiegeloog, een zwart gat in de volgepropte visuele wereld van de spiegelkamer. Echter, omdat ik in de spiegelkamer tegelijkertijd beschik over alle mogelijke gezichtspunten van mijn lichaam - en ik zie ook mijn eigen kijken naar mijn lichaam versmelten deze tot een hallucinerende ervaring van de totaliliteit van mijn lichaam ais subject en object van de ervaring. 
Gewaardeerde toehoorders,

We kunnen ons eigen lichaam maar heel beperki direct, zonder tussenkomst van hulpmiddelen en technieken, waarnemen. We willen onze eigen rug met onze eigen ogen zien, maar dat lukt nooit zonder gebruik te maken van bijvoorbeeld spiegels. Het binnenste van ons eigen lichaam zullen slechts enkele ongelukkigen onder ons rechtstreeks zien: in normale omstandigheden moeten we gebruik maken van een mediërende visualiseringstechniek als bijvoorbeeld Röntgenstralen. Deze beperktheid is van invloed op elke reflectie op het lichaam. Het is alsof Leonardo zich dit beperkte zicht op het lichaam (als subject en object van de ervaring) realiseerde en daarom een apparaat heeft ontworpen dat deze kwestie ten top gevoerd aan ons toont.

Gezien zijn fascinatie voor het menselijk lichaam, is het zeer aannemelijk dat Leonardo deze spiegelkamer heeft bedacht om iets over het lichaam te weten te komen. Gedurende zijn hele leven heeft Leonardo zich met opmerkelijke vasthoudendheid beziggehouden met het ontraadselen van de geheimen van de menselijke anatomie. Hij heeft een aantal menselijke lichamen werkelijk ontleed en de resultaten hiervan in wonderbaarlijk mooie tekeningen vastgelegd. Leonardo's anatomische onderzoekingen behoren tot zijn belangrijkste wetenschappelijke prestaties: hij heeft anatomische inzichten en ontdekkingen getekend en beschreven die voordien niet bekend waren of in ieder geval nooit waren beschreven, zoals het functioneren van de hartkleppen, de capillaire werking van vaten en aderverkalking. ${ }^{6}$

We kunnen Leonardo's spiegelkamer op die grond beschouwen als een apparaat dat hij heeft ontworpen in het kader van of gemotiveerd door zijn anatomische onderzoekingen. Waarbij we moeten opmerken dat deze onderzoekingen wat betreft Leonardo niet alleen waren gericht op pure anatomische kennis maar ook dienden om kennis te verkrijgen over wie en wat de mens is in een meer filosofische zin.

De spiegelkamer dwingt, letterlijk en figuurlijk, tot reflectie. Het apparaat reflecteert en zet aan tot reflecteren bij de gebruiker. Het is 
een symbool voor een houding ten aanzien van de werkelijkheid die kenmerkend is voor zowel kunst als wetenschap, d.i. een reflexieve houding.

Het apparaat noodt de gebruiker tot reflectie over zichzelf: wie ben ik, wat ben ik, waar ben ik, hoe zie ik er uit, hoe kijk ik tegen mijzelf aan en hoe zien anderen mij? Wat dat betreft geeft het apparaat een symbolisch beeld van onze aanwezigheid in de wereld met andere mensen. $\mathrm{U}$, gewaardeerde toehoorders, voor wie ik een uurtje geleden bereidwillig deze jurk heb aangetrokken om in ieder geval aan uw minimaalste verwachtingen omtrent deze bijeenkomst te voldoen, vormt mijn spiegelkamer. Mijn woorden en gebaren zie ik in u gereflecteerd.

De spiegelkamer opgevat als een metafoor voor onze aanwezigheid in de wereld kan als een mogelijke verklaring dienen voor de houding van de getekende figuur. Het lijkt alsof de figuur een stok in zijn hand heeft die hij dreigend-afwerend omhoog houdt. Uit beschrijvingen van tijdgenoten komt Leonardo naar voren als iemand die de neiging had om zichzelf af te schermen tegen indringers uit de buitenwereld. ${ }^{7}$

We kunnen de spiegelkamer ook beschouwen in het licht van Leonardo's interesse in de optica, een andere wetenschap waarmee hij zich, zoals blijkt uit zijn manuscripten, fanatiek bezighield. Spiegels hebben in deze onderzoekingen altijd een zeer belangrijke rol gespeeld. ${ }^{8}$ Bijvoorbeeld tijdens zijn verblijf in Rome in 1513 besteedde hij veel tijd en energie aan de constructie van parabolische spiegels. Leonardo kan dit apparaat hebben bedacht om de gang van lichtstralen en andere optische fenomenen te onderzoeken. In dat geval zou de stok wellicht een hulpmiddel kumnen zijn bij dat onderzoek.

Gewaardeerde toehoorders,

In alle toepassingen die $\mathrm{ik}$ heb beschreven, wordt de spiegelkamer gebruikt voor of is het een onderdeel van een experiment. Iets nauwkeuriger uitgedrukt: de spiegelkamer maakt een aantal experimenten mogelijk. Door het gebruik ervan kunnen we iets leren over de feno- 
menen in de wereld. We kunnen kennis verkrijgen die we in een normale situatie niet zonder meer kunnen opbouwen.

Met het apparaat kunnen experimenten worden uitgevoerd die te vergelijken zijn met bijwoorbeeld de z.g. "mimetische experimenten" uit de Victoriaanse tijd, waarin werd geprobeerd om natuurlijke fysische fenomenen in al hun complexiteit te reproduceren in een laboratorium, zoals de cloud chamber (wolkenkamer - afbeelding 2) van Charles Thomson Rees Wilson (1869-1959). Een apparaat dat in eerste instantie was bedoeld om meteorologische fenomenen, zoals wolken, in gecontroleerde omstandigheden na te bootsen om ze te kunnen bestuderen." In Leonardo's spiegelkamer wordt bijvoorbeeld een experiment uitgevoerd op het gebied van de optica. Het gedrag van lichtstralen wordt hier onder extreme omstandigheden opgewekt door de aanwezigheid van de experimentator zelf. Want dat is cruciaal in Leonardo's experiment (en te vergelijken met Wilsons cloud chamber): de lijfelijke aanwezigheid van de experimentator, zijn bewegingen maar ook zijn kijken bepalen de loop van het experiment. Leonardo maakt zichzelf tot onderdeel van een experiment, in een apparaat dat ook alleen maar 'werkt' als hij er een fysiek onderdeel van wordt. De experimentator is geen buitenstaander; als de experimentator het apparaat aanzet (door naar binnen te gaan) verliest hij tegelijkertijd de controle over het apparaat. Alleen door uit het apparaat te stappen kan het weer worden uitgezet en wordt het experiment stilgezet. Hierbij moet worden opgemerkt dat het apparaat tijdens het experiment als het ware onzichtbaar wordt; de experimentator in het apparaat ziet niet het apparaat maar alleen zijn werking. Dat geeft aan het experiment een objectieve status. Het lijkt alsof het apparaat de werkelijkheid niet medieert maar rechtstreeks toont. 


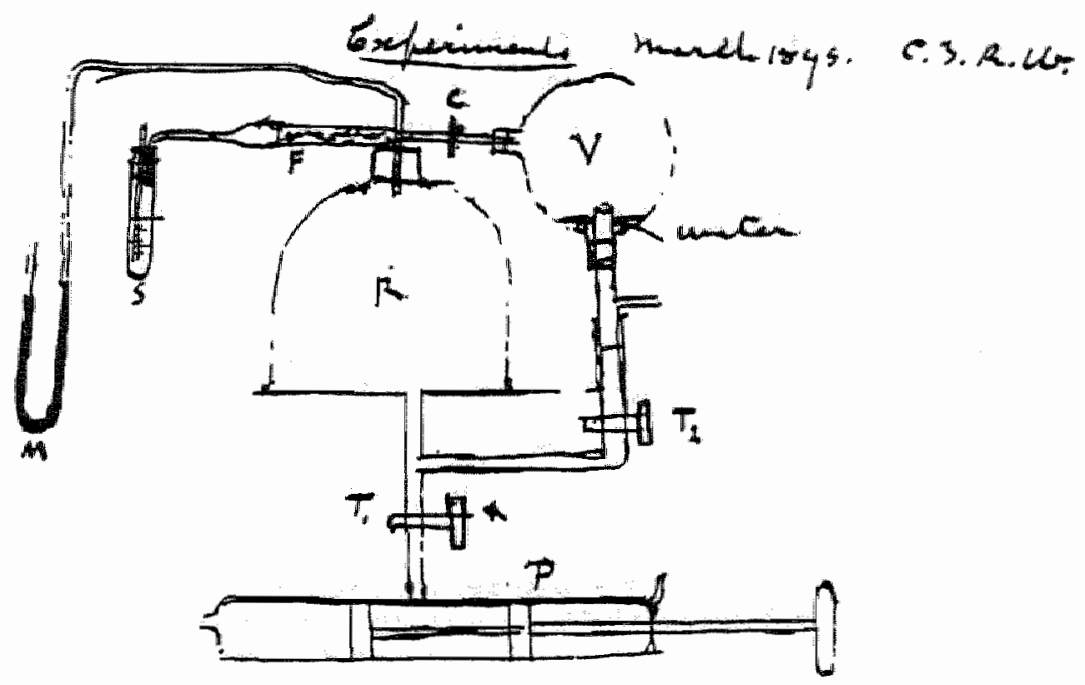

Afbeelding 2: C.T.R. Wilson, notebook A1, March 1895 (cloud chamber apparatus). 
De spiegelkamer nodigt uit om na te denken over wat het voor ons betekent om een onderdeel van een apparaat te worden, over wat het betekent dat ons lichaam interfereert, overlapt en samenwerkt met een apparaat. Wat betekent het dat we zijn opgesloten in een apparaat dat ons een plaats geeft, ons lichaam uitbreidt en onze kennis vermeerdert? Bij dit experiment is er bovendien sprake van een betrokkenheid bij en een lichamelijke en intellectuele onderworpenheid aan het experiment, die bij het moderne 'wetenschappelijke' experiment uit den boze lijken. Leonardo creëert niet alleen een wetenschappelijk experiment maar hij creëert tegelijkertijd een situatie waarin hij zichzelf confronteert met de effecten en consequenties van zijn eigen verzinsels. $\mathbb{H i j}$ roept op die manier een ervaring op die een cruciaal element van het experiment is en dat daardoor de status van een wetenschappelijk experiment lijkt te verliezen.

De conclusie kan niets anders zijn dan dat het oproepen van de bijzondere ervaring in de spiegelkamer tegelijkertijd een artistiek en een wetenschappelijk experiment is en misschien zelfs een filosofisch experiment. Het is een lyrische omweg om iets te weten te komen over het eigen lichaam en over optische verschijnselen, op meerdere terreinen van kennis en ervaring.

Dat wil zeggen dat de spiegelkamer tegelijkertijd een wetenschappelijk apparaat en een interactief kunstwerk is. Dat is zeer bijzonder omdat, zoals ik eerder heb opgemerkt, een kunstwerk zich zeer moeilijk Jaat omvormen tot een wetenschappelijk apparaat.

Leonardo's spiegelkamer doet bijvoorbeeld denken aan sommige videoinstallaties van Bill Viola, waarin de toeschouwer op een zelfde wijze een onderdeel is van de installatie en door de bewegingen van zijn/haar lichaarn invloed uitoefent op wat er is te zien. Onze aanwezigheid als beschouwer verandert het aanzien van de video-installatie. De spiegelkamer als kunstwerk beschouwd, kan ons iets leren over de invloed van onze blik en van onze aanwezigheid op een kunstwerk en over onze lichamelijke en intellectuele positie ten opzichte van een kunstwerk. 
Bij dit alles moeten we wel bedenken, dat we niet weten of Leonardo dit ontwerp ooit heeft uitgevoerd; voor zover ik Leonardo ken ${ }^{10}$ - en gezien de afmetingen van de spiegels ${ }^{11}$ - heeft hij dat waarschijnlijk niet gedaan. De tekening geeft een aanduiding van een mogelijk apparaat, van een mogelijke plaats voor een experiment. ${ }^{12}$ Het is bovendien niet duidelijk of Leonardo dit apparaat voor een specifiek doel heeft ontworpen of alleen maar benieuwd was naar wat er zou gebeuren als hij erin stond. Daarnaast moeten we ook de "kermisachtige' inslag van het apparaat onderkennen. Leonardo heeft meer apparaten en automaten ter vermaak ontworpen en hij beschrijft een aantal practical jokes, zoals het teweegbrengen van een lichtflits met behulp van chemicaliën in een kamer met mensen. ${ }^{13}$ Een vorm van practical joking die duidt op een heel bijzonder gevoel voor humor.

De spiegelkamer is in de eerste plaats een gedachte-experiment, ook in die zin dat het leidt tot nieuwe gedachte-experimenten, zoals u net - ik hoop naar genoegen - hebt kunnen ervaren, want ook ik heb nooit in zo'n apparaat gestaan.

\section{Gewaardeerde toehoorders,}

Ik hoop dat $\mathrm{u}$ inmiddels aanvoelt waar ik heen wil. Zowel kunstenaars als wetenschappers houden zich bezig met onderzoek en proefneming. Om de rellatie tussen wetenschap en kunst te onderzoeken moeten we ons richten op het wetenschappelijke en artistieke experiment en op de rol van het lichaam daarin. Meer in het algemeen moeten we ons richten op de wijze waarop het lichaam in kunst en wetenschap door, in of met apparaten of andere mediërende technieken, in ieder geval via een complexe omweg, wordt ervaren en gerepresenteerd met als doel om kennis te verkarijgen. In een onderzoek naar de relatie tussen kunst en wetenschap moet het menselijk lichaam en de lichamelijkheid centraal staan.

Het is duidelijk dat Leonardo zijn eigen lichaam en lichamelijkheid in het artistieke en wetenschappelijke experiment niet negeert. Leonardo zet zijn lichaam in de spiegelkamer heel doelbewust in in een experiment. Dit heeft te maken met het feit dat volgens Leonardo een weten- 
schapper zonder lichaam niet mogelijk is; zoals ik dat elders heb betoogd. ${ }^{14}$ Dat lijkt een open deur, maar als we kijken naar de wijze waarop in de loop van de tijd de ontwikkeling van het wetenschappelijke denken is beschreven dan valt op hoe weinig aandacht er is besteed aan die rol van het lichaam van de wetenschapper en aan lichamelijkheid in het wetenschappelijke denken en experiment. Pas recent is er meer aandacht gekomen voor de "belichaamde wetenschap', voor het feit dat er zonder vlees geen bewustzijn en ideeën kunnen zijn en voor de onmogelijkheid van een lichaamloze wetenschapper ${ }^{15}$ Leonardo"s spiegelkamer geeft een hint om deze lichamelijke aspecten van wetenschap te onderzoeken op het raakvlak van wetenschappelijke en artistieke experimenten.

Het experiment van de kunstenaar heeft uiteindelijk als doel om zijn/haar eigen intellectuele en lichamelijke relatie tot de wereld te bepalen. In zijn/haar experimenten heeft de kunstenaar uitdrukkelijk aandacht voor zichzelf als intellectueel en lichamelijk middelpunt. Het artistieke experiment wordt gebruikt om een ervaring op te wekken die kan worden ingezet bij het maken van een kunstwerk.

Leonardo geeft een intrigerend voorbeeld van de wijze waarop een atelier kan dienen als een experimentele ruimte. In een van zijn manuscripten tekent en beschrijft hij hoe zonlicht door een kruisvormige opening in een afgeschermd raam van een kamer naar binnen valt en de vorm van een crucifix projecteert op de muur tegenover het raam. Wat Leonardo in feite beschrijft, is hoe een kamer is om te bouwen tot een camera obscura; een apparaat dat hij meerdere malen beschrijft in zijn manuscripten. ${ }^{16}$ Door een kleine opening in een geblindeerd raam kan een beeld van de buitenwereld geprojecteerd worden op de binnenmulir van een kamer, bijvoorbeeld het atelier van de kunstenaar. Dat is een evocerend beeld met veel implicaties die ook na Leonardo door andere kunstenaars zijn overdacht. Er is bijvoorbeeld een gravure bekend van Althanasius Kirchner uit 1646 die een levensgrote camera obscura laat zien waarin een schilder staat, die het beeld van de buitenwereld dat op een doek wordt geprojecteerd, naschildert. Het atelier 
van de schilder als camera obscura is een experiment dat de schilder kan inzetten bij het maken van een kunstwerk.

Een dergelijk beeld van een atelier als camera obscura laat zien hoe een kunstenaar tegen zijn atelier aankijkt. De ruimte waar het artistieke experiment plaatsvindt, het atelier van de kunstenaar (maar dat kan tegenwoordig ook een virtuele ruimte zijn, zoals de web site van een kunstenaar), is een plek waar de wereld op gecontroleerde of ongecontroleerde wijze wordt binnen gehaald om intensieve aandacht aan haar te besteden. Dat kan ook gebeuren door bijvoorbeeld een model uit te nodigen of door het uitstallen van de voorwerpen voor een stilleven. Het atelier zelf kan ook onderwerp zijn van een kunstwerk. ${ }^{17}$ Het atelier is een omlijsting waarbinnen de kunstenaar functioneert; waarvan hij/zij gebruik maakt, dat hij/zij modelleert naar zijn/haar lichamelijke en intellectuele wensen, en als zodanig kan het atelier ook functioneren als een instrument. De experimenten die de kunstenaar uitvoert, worden derhallve bepaald door deze omlijsting.

Aandacht voor het experiment betekent ook aandacht voor de architectuur en de inrichting van het wetenschappelijke laboratorium en het atelier: welke ruimte krijgt het lichaam en de lichamelijkheid toegewezen in een laboratorium en in een atelier? ${ }^{18}$

De rol van de observator in het wetenschappelijke experiment is uiteraard ook van belang. In de twintigste eeuw is de belangrijke en sturende rol van de observator in het wetenschappelijke experiment onderkend en uitgebreid bestudeerd. Hoe zit het met het lichamelijke aspect van deze rol en wat kunnen we hierover meer te weten komen als we kijken naar de lichamelijke ervaring van de kunstenaar in het artistieke experiment?

Gewaardeerde toehoorders,

Vanaf de veertiende eeuw is samenwerking en uitwisseling van kennis en methoden tussen kunstenaars en anatomen altijd gebruikelijk geweest. De ervaring en inzichten die worden opgedaan door de anatoom tijdens een anatomische ontleding kunnen pas 'wetenschap- 
pelijke" kennis worden als zij worden vastgelegd in een medium buiten de geest en het lichaam van de anatoom. De anatoom heeft een kunstenaar nodig om in een tekening zichtbaar en kenbaar te maken wat hij (de anatoom) met behulp van het mes, zijn waarneming en zijn theorieèn op het lichaam heeft veroverd. Anatomische tekeningen hebben een centrale en onmisbare rol vervuld in de verbreiding en uitbreiding van anatomische kennis. ${ }^{19}$

Een voor de hand liggende vragg in verband met deze anatomische tekeningen is op welke wijze esthetische strategieên of vormen, die we terug zien in contemporaine kunst, van belang zijn voor de (wijze van) anatomische theorievorming, en op welke wijze esthetische strategieen en vormen worden ingezet om de beschouwer te overtuigen van de waarheid van de gepresenteerde anatomische werkelijkheid. Dat betekent dat in een bespreking van anatomische tekeningen, esthetische, wetenschapshistorische en -filosofische vragen en problemen door elkaar heen lopen; er is geen uitputtende monodisciplinaire invalshoek op deze tekeningen mogelijk. Een anatomische tekening is niet zelden zowel een kunstwerk als een wetenschappelijk "traktaat". Het reeds bestaande onderzoek naar de geschiedenis en ontwikkeling van de anatomische tekening kan worden uitgebreid door de zintuiglijke en lichamelijke ervaring (meer in het bijzonder de tast en de visuele ervaring) van de anatoom, de tekenaar en de beschouwer van de tekeningen te thematiseren. Hoe wordt de zintuiglijke en lichamelijke ervaring van de anatoom tijdens een ontleding door de kunstenaar vastgelegd of opgenomen in een tekening? Hoe wordt een anatomische tekening intellectueel begrepen en lichamelijk herbeleefd door de beschouwer?

Sinds de uitvinding van de fotografie en medische visualiseringstechnieken als de Röntgenstralen lijkt de samenwerking tussen anatomen en kunstenaars, met als doel het representeren en ontwikkelen van anatomische kennis, niet langer noodzakelijk. De laatste jaren zijn er bovendien allerlei nieuwe medische visualiseringstechnieken ontstaan als endoscopie, ultrageluid, CAT scans, MRI (magnetic resonance), CT (computerized tomography) en PET (positron emis- 
sion tomography) waarmee de binnenkant van het menselijk lichaam op verbluffende wijze kan worden gevisualiseerd. Liggend op de onderzoekstafel, al dan miet omsloten door een apparaat, kunnen we ons eigen lichaam van binnen, bij wijze van spreken fluitend en in 'real time', op een beeldscherm aanschouwen. Tenminste, zo lijkt het, want tegenover de beelden die we op het beeldscherm zien, zijn we aanvankelijk even hulpeloos als Leonardo tegenover de reflecties in zijn spiegelkamer. De transparantie die deze apparaten lijken te bieden, is uiteraard een illusie. ${ }^{20}$ De beelden die wij zien, zijn een vertaling van de elektronische signalen, die door deze apparaten worden gegenereerd, naar een elektronisch beeld op een scherm. Er is een handleiding nodig om deze beelden te kunnen begrijpen als een afbeelding van iets dat zich in ons lichaam bevindt. Door de ontwerpers zijn in de vertaalprocedure allerlei keuzes gemaakt omtrent de status en de zichtbaarheid van de voor ons onzichtbare delen van het lichaam. Er wordt bij het zichtbaar maken bovendien gebruik gemaakt van allerlei esthetische conventies. Wat het lichaam is en wat wij als mens er van vinden, wat het betekent dat wij een lichaam zijn en hebben, is diep verborgen aangebracht in deze vertaling, of beter gezegd is de (vaak onbegrepen of ongereflecteerde) motor van de vertaling van signaal naar beeld.

De vijftiende- en zestiende-eeuwse anatomen zagen in het geopende lichaam vaak niet meer dan wat zij lazen in de Middeleeuwse medische handboeken, de autoriteiten van hun tijd. Ook wij zien niet veel meer dan wij al weten, ondanks de nieuwe visualiseringstechnieken. Trouwens, wat weten wij eigenlijk meer van ons lichaam door deze apparaten dan voorheen en hoe is de ervaring van ons lichaam en onze kijk op lichamelijkheid door deze apparaten veranderd?

Het antwoord op dit soort vragen vinden we niet in medische handboeken, maar - en dat is niet toevallig - in moderne kunst waarin gebruik wordt gemaakt van deze moderne medische visualiseringstechnieken. Hedendaagse kunstenaars als Zoe Leonards, Kiki Smith, Cindy Sherman, Mike Kelley, Helen Chadwick, Mona Haw toum, Stansfield \& Hooykaas en Richard Kriesche hebben deze nieu- 
we medische visualiseringtechnieken toegepast in of onderdeel gemakkt van hun werk. In dat werk draait het waak om kwesties als het lichaam dat $\mathrm{ik}$ ben en het lichaam dat ik heb, de ervaring van het lichaam en de lichamelijkheid, het zelf en de ander, de grenzen tussen subject en object en de relatie tussen het lichaam en technologie. ${ }^{21}$ Kwesties die we ook al tegenkwamen - opnieuw: dat is denk ik niet toevallig - bij de bespreking van Leonardo's spiegelkamer.

Toen Leonardo zijn spiegelkamer bedacht en in een onooglijk schetsje tekende, gaf hij in een handomdraai weer waar het om draait als we ons lichaam willen leren kennen, zowel het lichaam dat we hebben als het lichaam dat we zijn. We hebben daarvoor een medium nodig, zoals een blad papier of een apparaat. Tegelijkertijd moeten we een positie innemen tegenover dat gemedieerde lichaam en dat betekent een wetenschappelijke maar ook een artistieke en filosofische reflectie op het lichaam uitvoeren. Als we omvattende kennis van het menselijk lichaam willen verkrijgen, van hoe we er van binnen en van buiten uitzien en van de ervaring van ons lichaam en onze lichamelijkheid, dan kunnen we niet zonder kunst en wetenschap, die de noodzakelijke vormgevende activiteiten zijn om tot deze kennis te komen. Dat wil zeggen dat het gereflecteerde menselijk lichaam de plaats is waar kunst en wetenschap noodzakelijkerwijs en vaak onontwarbaar samenvallen. Een onderzoek naar de relatie tussen kunst en wetenschap moet beginnen bij het gereflecteerde lichaam. 
Gewaardeerde toehoorders,

Nu ik aan het eind van mijn oratie ben gekomen, en naar ik hoop u heb weten te overtuigen van het belang van de leeropdracht en van mijn voomemen om aan dit belang recht te doen, wil ik graag een woord van dank uitspreken. Ik sta hier in het volle besef dat zonder de hulp, steun en vertrouwen van velen ik hier wellicht niet had gestaan.

Allereerst wil ik Het College van Bestuur bedanken voor het in mij gestelde vertrouwen. Het is mij opgevallen dat Het College van Bestuur de Faculteit der Cultuurwetenschappen een zeer warm hart toedraagt. Dat heeft ongetwijfeld te maken met het streven van de Faculteit om waarlijk interdisciplinair te zijn door in het onderzoek en het onderwijs niet op voorhand een bepaalde theoretisehe benadering te laten prevaleren. Daarbij geldt, zoals de heer Dittrich zo treffend heeft geformuleerd bij de opening van dit academisch jaar: 'vernieuwing ligt vaak op het snijvlak van disciplines. ${ }^{, 22}$

Het Bestuur van de Edmond Hustinx Stichting ben ik bijzonder er. kentelijk voor mijn benoeming op de door de stichting ingestelde leerstoel kunstgeschiedenis in relatie tot de ontwikkeling van natuurwetenschap en techniek.

Ook dank ik Het Faculteitsbestuur voor het vertrouwen dat het in mij heeft gesteld. Vanaf het begin van mijn aanstelling heeft het Bestuur mij met raad en daad ondersteund; ik heb dat ervaren als een uiting van het belang dat de Faculteit hecht aan deze bijzondere leerstoel.

Ik wil ook mijn nieuwe collega's van de Faculteit der Cultuurwetenschappen bedanken voor hun zeer gastvrije en vriendschappelijke onthaal en voor de inspirerende werkomgeving die zij samen in de loop van de jaren met zo weel enthousiasme hebben gevormd en waarvan ik nu kan profiteren. In het bijzonder noem ik Ruth Benschop en Geert Somsen. Veel ideeên over het experiment heb ik ontleend aan onze samenwerking, die zal leiden tot een internationale workshop over experimenteren in kunst en wetenschap. Natuurlijk noem ik José van Dijck, Renée van de Vall, Jo Wachelder en Bernike Pasveer. 
Vanaf het begin wan mijn aanstelling aan de Faculteit hebben wij intensief (en wat mij betreft met veel plezier) samengewerkt aan het schrijven van het onderzoeksprogramma 'The Mediated Body'. Veel wan mijn ideeën over de rol van het menselijk lichaam in kunst en wetenschap zijn gevormd tijdens deze samenwerking.

Ik dank Cornelis Verhoeven en Arjo Vanderjagt, mijn inspirerende promoteres: Verhoeven heeft een beslissende invloed gehad op mijn filosofische vorming, niet in de laatste plaats door één zin uit zijn werk die behalve waar ook heel erg leuk is: "Wat wij ook denken, het verplicht de realiteit tot niets". ${ }^{23}$ Op de steun en hulp van Arjo Vanderjagt kon en kan ik altijd rekenen, als begeleider en als promotor en nu als collega in Groningen.

Met weemoed denk ik terug aan mijn verblijf aan de Faculteit der Wijsbegeerte in Amsterdam, als student, promovendus en docent; dat is in de eerste plaats vanwege de prettige collega's aldaar. Deze excollega's zijn in niet onbelangrijke mate verantwoordelijk geweest voor mijn academische vorming, of misschien beter gezegd, opvoeding. Zij kunnen nu constateren dat dat nog niet helemaal is gelukt.

Ik dank mijn huidige collega"s aan de Faculteit der Wijsbegeerte in Groningen, mijn filosofische thuisbasis, waar het zeer goed toeven is en waar ik mij kan laven aan bijna verboden monodisciplinaire vruchten, die niettemin van onschatbaar belang zijn voor mijn Maastrichtse interdisciplinaire onderzoek.

Ik ben zeer blij dat ik mijn familie kan bedanken, in het bijzonder mijn moeder en mijn zus Sariska: zonder hen had ik hier niet gestaan.

Ik dank Catharina Meddens, collega-filosoof en partner in crime, die mij elke dag weer laat zien welke dingen echt belangrijk zijn in het leven. 
Gewaardeerde toehoorders,

Ik heb Leonardo da Vinci aan u gepresenteerd als mijn inspirator van het onderzoek naar de relatie tussen kunst en wetenschap. Op een bladzijde in één van zijn manuscripten die vol staat met geometrische onderzoekingen breekt hij de laatste zin plots af met een '\&c', waarna hij schrijft: 'omdat de soep koud wordt:. ${ }^{24}$ Het is één van de mooiste en meest diepzinnige zinnen die Leonardo heeft geschreven. Kunst en wetenschap kunnen wel even wachten, maar wat niet kan wachten is de warme soep die samen met vrienden moet worden gegeten.

\section{IK HEB GEZEGD.}


\& 


\section{AANTEKENINGEN}

1 Bijvoorbeeld James W. McAllister, Beauty and Revolution in Science, Ithaca \& London: Cornell University Press 1996; Brian S. Baigrie (ed.), Picturing Knowledge. Historical and Philosophical Problems Concerning the Use of Art in Science, Toronto, Buffalo, London: University of Toronto Press 1996; Caroline A. Jones \& Peter Galison (eds.), Picturing Science, Producing Art, New York/London: Routledge 1998.

${ }^{2}$ C.P. Snow, The Two Cultures, Cambridge University Press 1993.

${ }^{3}$ Zie Carlo Pedretti, The Literary Works of Leonardo da Vinci, compiled and edited from the original manuscripts by Jean Paul Richter. Commentary, 2 vols., Oxford: Phaidon 1977, I, p. 136. Serge Bramley, Léonard de Vinci, Paris: J-C. Lattès 1988, p. 16, brengt dit apparaat in verband met Leonardo's zelfportret (circa 1512) dat hij misschien heeft getekend met behulp van spiegels.

"Hermann Kern, Labyrinte. Erscheinungsformen und Deutungen. 5000 Jahre Gegenwart eines Urbilds, München: Prestel 1982, p. 268 , beschrijft dat op een labyrint-tentoonstelling (waar zijn boek de catalogus van is) Leonardo's apparaat is nagebouwd en dat het diende als Herzstück van de tentoonstelling; het apparaat gaf het publiek een directe en indringende labyrintervaring.

${ }_{5}$ Voor een uitgebreide behandeling van dit onderscheid, zie $\mathrm{M}$. Coolen, 'Het dubbele karakter van de lichamelijkheid van de mens', in: Filosofie, Jrg 9, nummer 5, oktober/november 1999, pp. 4-13.

${ }^{6}$ Zie Martin Clayton \& Ron Philo, Leonardo da Vinci - The Anatomy of Man, ex. cat. The Museum of Fine Arts Houston, Boston, Toronto \& London: Bulfinch Press 1992, p. 47.

${ }^{7}$ Zie Daniel Arasse, Leonardo da Vinci, translated by Rosetta Translations, London: Greenwich Editions 1997, pp. 475-487. "Ook in zijn overdenkingen over de schilderkunst spelen spiegels een belangrijke rol, zie Pedretti, The literary Works 1, pp. 183-185. 'Zie Peter Galison and Alexi Assmus, 'Artificial clouds, real particles', in: D. Gooding, T. Pinch, S. Schaffer (eds), The Uses of Experiment, Cambridge University Press 1989, pp. 225-274. 
"Zie Robert Zwijnenberg, The Writings and Drawings of Leonardo da Vinci. Order and Chaos in Early Modern Thought, translated by C.A. van Eck, Cambridge University Press 1999.

"Leonardo eindigt zijn beschrijving van de spiegelkamer met de opmerking dat hetzelfde effect zal optreden bij het gebruik van vier spiegels. Volgens Kern, Labyrinte, p. 268, duidt dit op Leonardo's besef dat het project op technische gronden niet kon worden uitgevoerd.

${ }^{12}$ Cf. Kim Veltman, Leonardo"s Method, Brescia: Centro Ricerche Leonardiane 1993, pp. 26-40.

${ }^{13}$ Ms. Forster $\mathrm{I}^{2}, 44 \mathrm{~b}, \mathrm{c}$. 1487-90.

${ }^{14}$ Zie Zwijnenberg, The Writings and Drawings, pp. 46-59.

${ }^{15}$ Cf. Christopher Lawrence \& Steven Shapin (eds.), Science Incarnate. Historical Embodiments of Natural Knowledge, Chicago \& London: The University of Chicago Press 1998.

${ }^{16}$ Zie Pedretti, The Literary Works, I, p. 137 en p. 133.

17 Zie Svetlana Alpers, "The Studio, the Laboratory, and the Vexations of Art', in: C.A. Jones \& $\mathbb{P}$. Galison, Picturing Science, Producing Art, New York/London: Routledge 1998, pp. 401-417.

${ }^{18}$ Cf. Peter Galison en Caroline A. Jones, 'Factory, Laboratory, Studio: Dispersing Sites of Production', in: The Architecture of Science, Cambridge: MIT 1999, p. 533.

${ }^{19}$ Zie K.B. Roberts and J.D.W. Tomlinson, The Fabric of the Body, Oxford: Clarendon Press 1992, pp. 7-10.

${ }^{20}$ Met dank aan José van Dijck en Bernike Pasveer die mij op deze technieken en kwesties hebben gewezen.

${ }^{21}$ Met dank aan Renée van de Vall die mij op deze kunstenaars en kwesties heeft gewezen.

${ }^{22}$ K.L.L.M. Dittrich, 'Academisch Leiderschap', in: Redes gehouden tijdens de opening van het Academisch Jaar 1999/2000 op 6 september 1999 en de 24e Dies Natalis op 7 januari 2000, s.l.e.a., p. 8.

${ }^{23}$ Comelis Verhoeven, Weerloos Denken, Baarn: Ambo 1982, p. 14. ${ }^{24}$ Manuscript Br.M. 254a, c. 1518; zie Pedretti, The Literary Works, II, p. 325. Cf. vergelijkbare opmerkingen in Michel De Montaigne, Essays, III, vertaling Frank de Graaff, Amsterdam: Boom 1993, pp. 387-390 (met dank aan Catharina Meddens woor deze verwijzing). 